\title{
Carbon monoxide poisoning causes optic neuropathy
}

Abstract

Purpose To describe the electrophysiological and psychophysical effects of carbon monoxide (CO) poisoning on visual function. Methods Three patients are presented who suffered $\mathrm{CO}$ poisoning, two due to suicide attempts and one in the course of a road traffic accident. After a full ocular examination, Goldmann visual fields, flash and pattern visual evoked potentials (VEPs) and flash and pattern electroretinograms (ERGs) were tested. Results Electrophysiology showed reduced or absent N95 components of the pattern ERG and delayed, reduced VEPs. A

positive-negative-positive (PNP) VEP waveform was seen in two cases. In one case, where presentation occurred at an early stage, visual and electrophysiological function was improved with hydroxycobalamine. Conclusions The combination of ERG and VEP findings suggest that $\mathrm{CO}$ poisoning can cause a toxic optic neuropathy that may have a similar aetiological mechanism to that in tobacco amblyopia. Early treatment with hydroxycobalamine may be of some benefit.

Key words Carbon monoxide poisoning, Electroretinography, Visual evoked potentials, Toxic optic neuropathy, Optic neuropathy

There have been a number of reports of cerebral cortical blindness following acute carbon monoxide (CO) poisoning. ${ }^{1-6}$ Neuroinvestigation using magnetic resonance imaging (MRI), computed tomography (CT) and regional blood flow studies using single photon emission computed tomography (SPECT) have identified evidence of occipital injury, ${ }^{4}$ diffuse white matter lesions, ${ }^{5,6}$ and cerebral ischaemia. ${ }^{1}$

Visual evoked potential (VEP) studies in CO poisoning have identified delays and morphological changes in both the flash and pattern $\mathrm{VEP}^{3,5-9}$ and two studies have suggested that there may be a lag period before the onset of secondary toxic changes. ${ }^{3,6}$ Some authors have suggested that evoked potential abnormalities indicate that a neurotoxicity occurs in $\mathrm{CO}$ poisoning. ${ }^{8,9}$ There have been no follow-up studies of VEP changes subsequent to $\mathrm{CO}$ poisoning, but one study has suggested a resolution of CT changes with time. ${ }^{2}$ To our knowledge, there have been no reports of pattern electroretinogram (PERG) abnormalities in $\mathrm{CO}$ poisoning.

We report three cases of visual loss following $\mathrm{CO}$ poisoning that have been investigated with VEPs and flash and pattern electroretinography.

\section{Methods}

VEPs were recorded using a two-channel montage with scalp electrodes positioned at the right and left occiputs $\left(\mathrm{O}_{1}, \mathrm{O}_{2}\right)$ and referred to a mid-frontal electrode $\left(\mathrm{F}_{\mathrm{z}}\right)$. Stimuli consisted of a diffuse flash stimulus of intensity 12 footlamberts (FtL) and a reversing black and white checkerboard pattern at $>90 \%$ contrast, of 1,2 and 4 cycle per degree (CPD) pattern size. All stimuli were presented at a rate of $2 \mathrm{~Hz}$ and were recorded using a Nicolet Spirit Clinical Averager employing a filter band pass of 1-70 Hz. One hundred averages were obtained for each stimulus.

Flash ERGs (FERG) were recorded using Burian-Allen contact lens electrodes referred to the outer canthus of each eye, according to ISCEV international guidelines. ${ }^{10}$ Stimulus was provided by a Ganzfeld standard flash of 2.8 FtL (scotopic) and 18.0 FtL (photopic) intensity. The filter band pass was $1-2000 \mathrm{~Hz}$. Scotopic ERGs were recorded after 20 min of dark adaptation.

Pattern ERGs (PERG) were recorded according to ISCEV standardisation guidelines using carbon fibre electrodes referred to the outer canthus of each eye. ${ }^{11}$ The stimulus consisted of a $2 \mathrm{~Hz}$ reversing black and white checkerboard of 0.5 and 1.0 CPD check size, presented at $>90 \%$ contrast. The filter band pass was $1-250 \mathrm{~Hz}$. One hundred and fifty averages were obtained for each stimulus programme, each programme being repeated three times. Artifact rejection was set at $50 \mu \mathrm{V}$.

Visual fields were performed using a Goldmann perimeter using a $0.25 \mathrm{~mm}^{2}$ target at 1.0, 0.1 and $0.0315 \mathrm{Asb}$ intensity (4/1E, 2/1E target sizes). P50 amplitudes were measured as well as the P50/N95 ratio. Our laboratory normal for the P50 component is $\geqslant 2.4 \mu \mathrm{V}$, and for the P50/N95 ratio, $\geqslant 0.75$.
I.G. Simmons, BVSC, FRCOphth Ophthalmology Department Chancellor Wing St James' University Hospital Beckett Street Leeds LS9 7TF, UK

Tel: +44 (0)1132433144 Fax: +44 (0)1132065028

P.A. Good Birmingham and Midland Eye Centre City Hospital Trust Birmingham, UK 


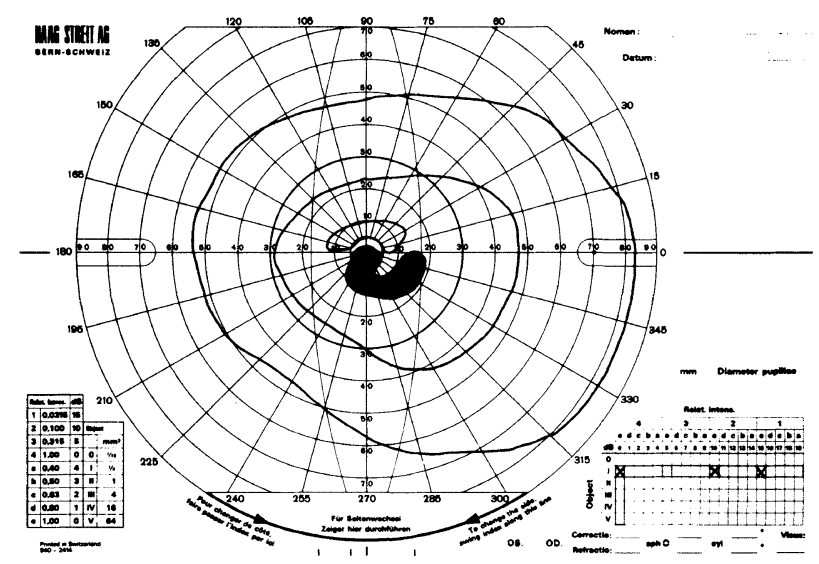

(a)

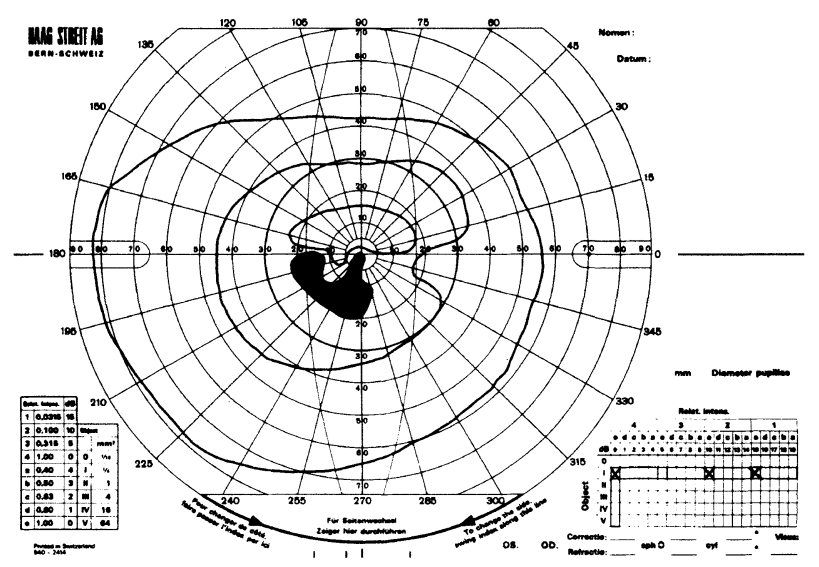

(b)

Fig. 1. Case 1. Left (a) and right (b) Goldmann fields before treatment.

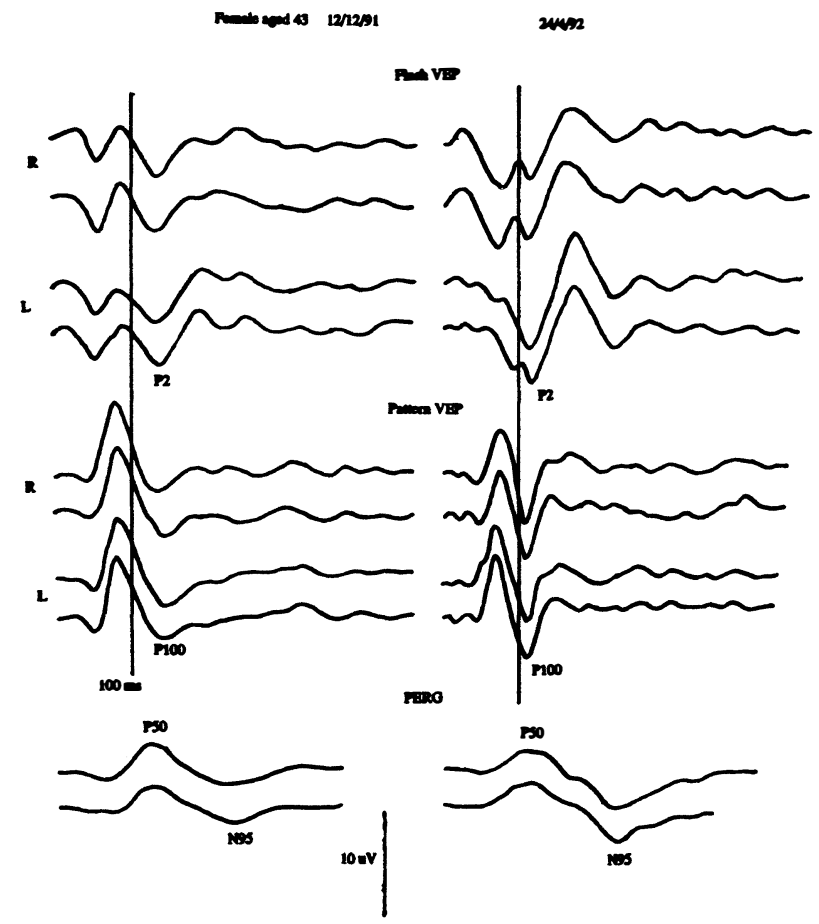

Fig. 2. Case 1. Pre- and post-treatment electrophysiological results (over-traced for clarity).

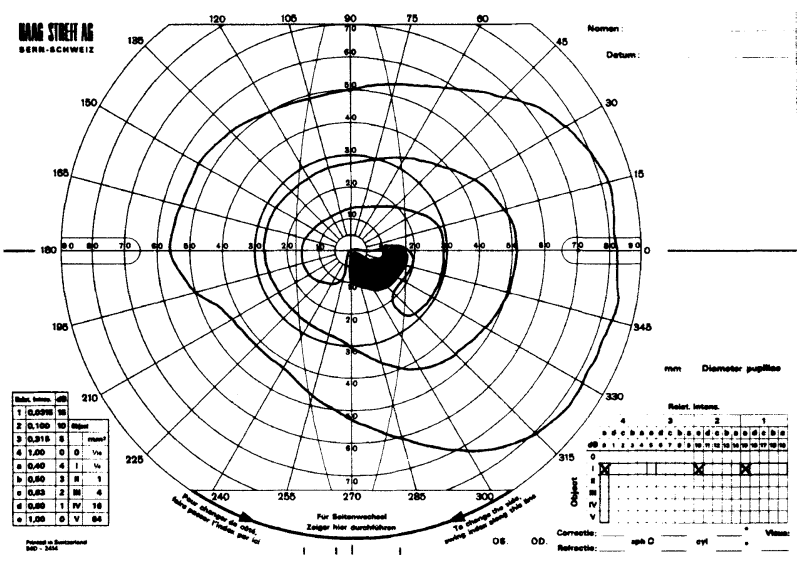

(a)

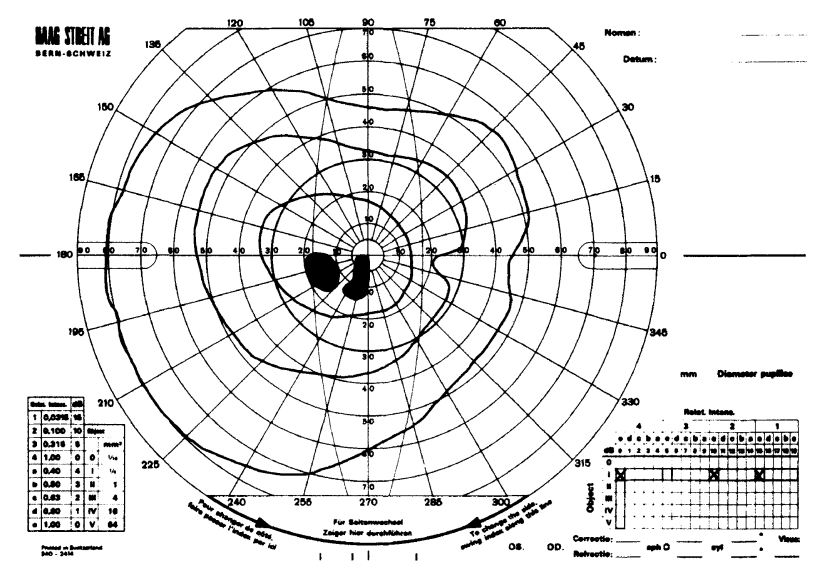

(b)

Fig. 3. Case 1. Left (a) and right (b) Goldmann fields after treatment. 


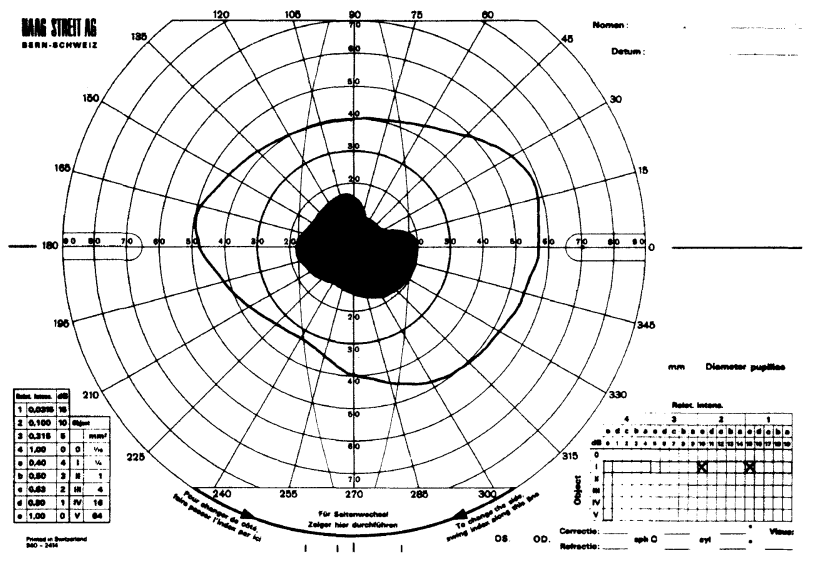

(a)

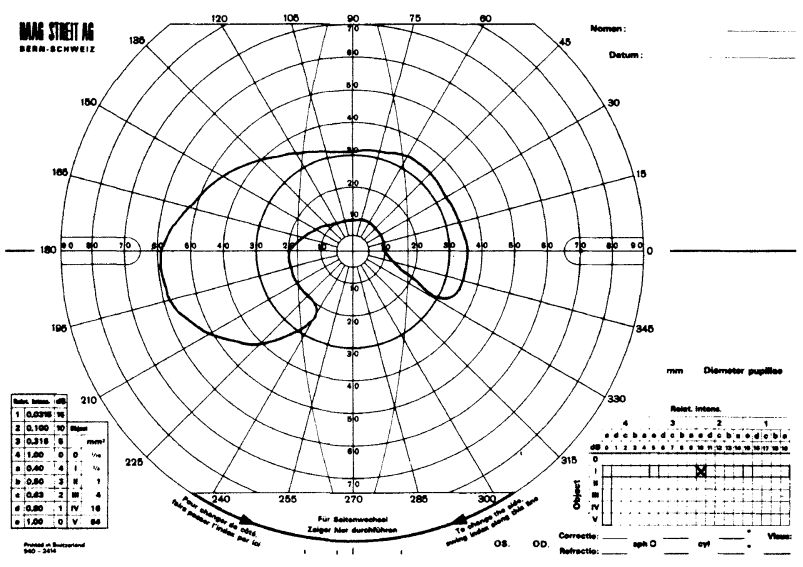

(b)

Fig. 4. Case 2. Left (a) and right (b) Goldmann fields.

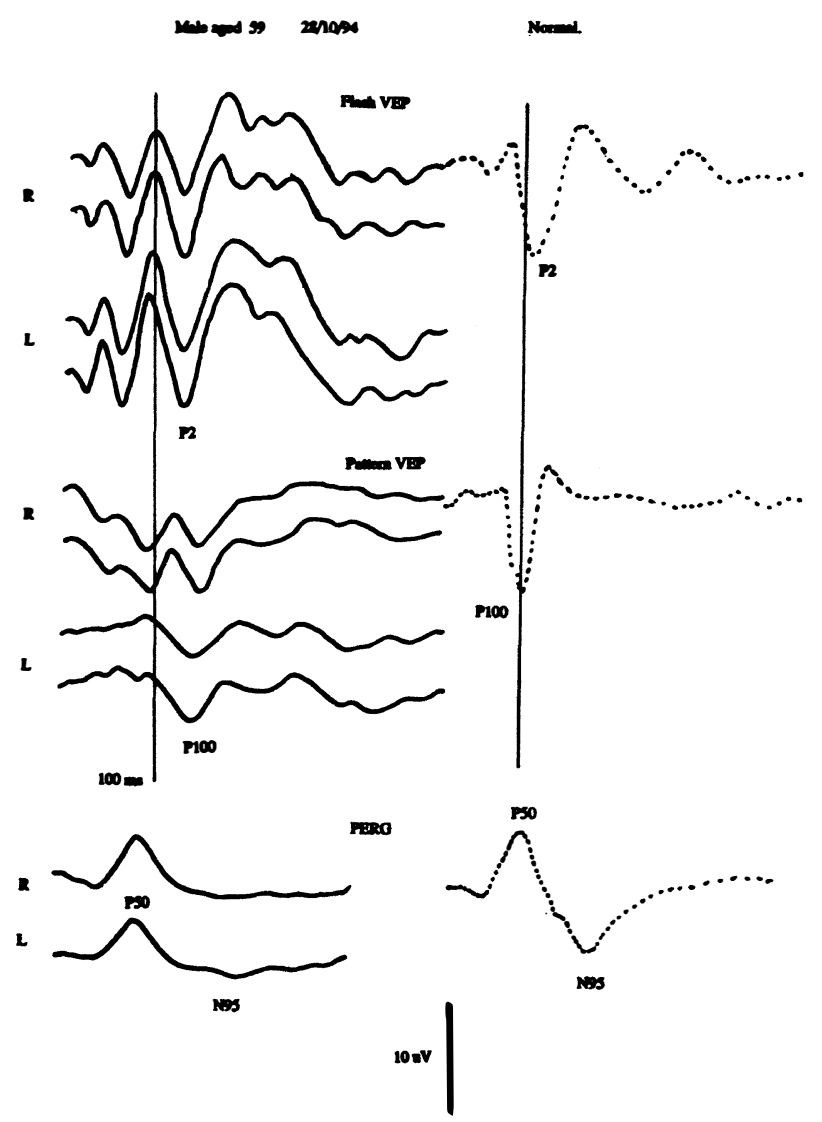

Fig. 5. Case 2. Electrophysiological results, together with normal examples (over-traced for clarity).

\section{Case reports}

\section{Case 1}

A 43-year-old Caucasian woman suffered $\mathrm{CO}$ poisoning following an attempted suicide (car exhaust pipe feeding back through a window). She presented 3 weeks later complaining of loss of central vision in both eyes. Her visual problems had developed over the 3 or 4 days subsequent to her suicide attempt. Visual acuities were 6/60 right eye and 6/36 left eye. Fundoscopy revealed bitemporal disc pallor with the visual fields showing bilateral paracentral scotomata, less dense on the left than the right (Fig. 1). The VEPs were of abnormal morphology to both flash and pattern stimulation, consisting of a positive-negative-positive (PNP) waveshape and a slight delay of the PVEP $(\mathrm{P} 100=126 \mathrm{~ms}$ right and left). PERGs had normal P50 components with a slight reduction of the N95 component in both eyes. The P50/N95 ratios were 0.84 and 0.78 in the right and left eyes respectively (note: normal $\leqslant 0.75$ ). FERGs were normal from both eyes to all stimuli (Fig. 2, left-hand traces).

At the time of her presentation, her systemic neurological examination was unremarkable as were the results of routine haematological and biochemical tests. (No information is available from the acute admission at the time of her suicide attempt.) 


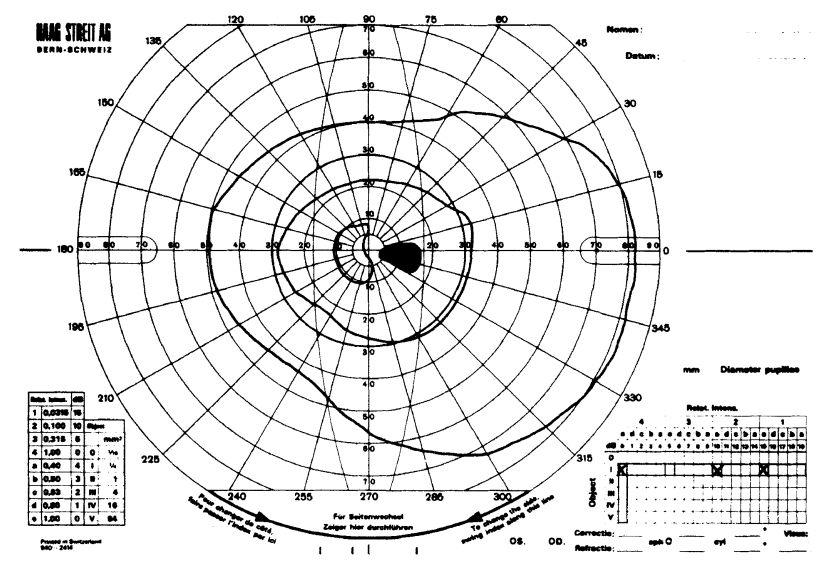

(a)

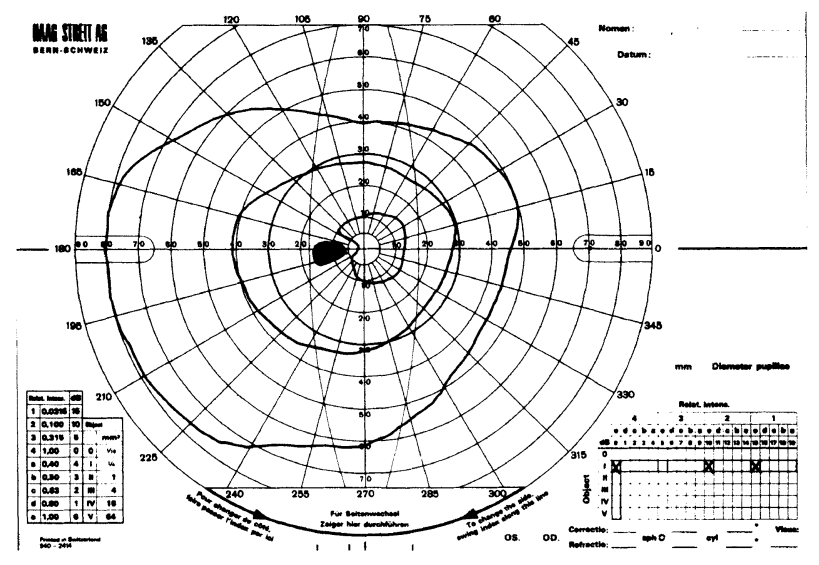

(b)

Fig. 6. Case 3. Left (a) and right (b) Goldman fields.

Fant VEP

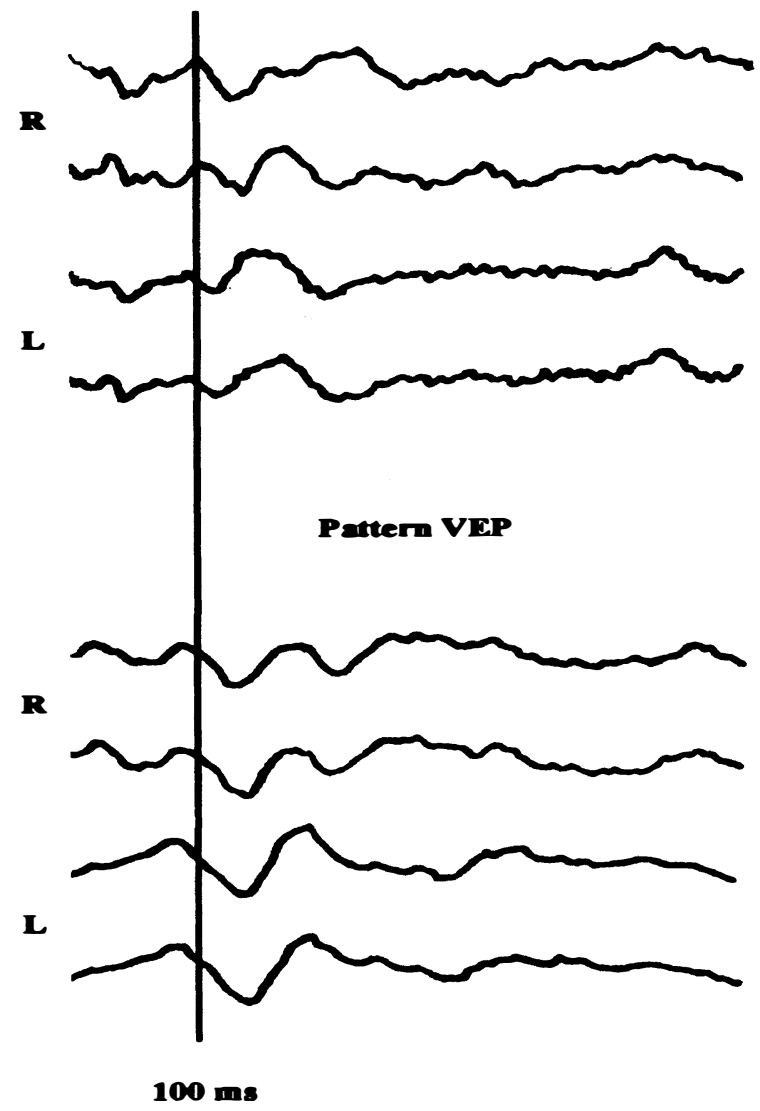

Pattem ERG

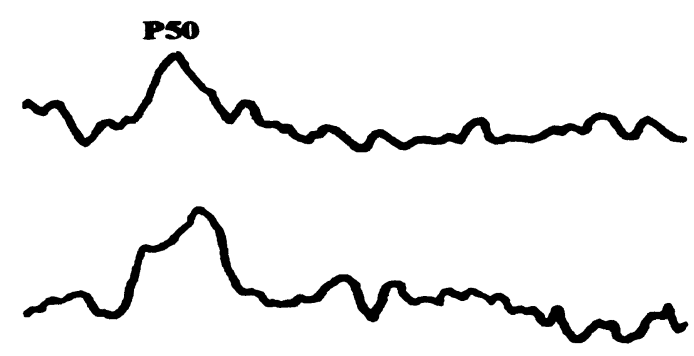

Fig. 7. Case 3. Electrophysiological results (over-traced for clarity). 
The patient was treated with hydroxycobalamine and on review, 6 weeks later, her acuity had improved to $6 / 36$ right eye and 6/18 left eye. There was an associated reduction in the size of the paracentrocecal scotoma in both eyes. VEPs were unchanged to flash stimulation, with a persistent PNP waveform. The PVEP showed an improvement in the amplitude and latency of the P100, the latter having improved to $120 \mathrm{~ms}$. PERGs were unchanged and FERGs were normal as before. Hydroxycobalamine was continued and she was reviewed 2 months later. Whilst her visual acuities and visual fields had remained unchanged (Fig. 3, showing a reduction in the scotomata), the FVEPs had become of earlier latency and were no longer of PNP waveshape. The PVEPs were now normal (P100 = $105 \mathrm{~ms}$ ) apart from a slightly negative waveform to small checks. PERGs were now normal from both eyes, the N95 component having increased in size to well within the normal range (Fig 2, right-hand traces). The P50/N95 ratios were 0.45 and 0.40 for the right and left eyes respectively (i.e. normal).

\section{Case 2}

A 59-year-old Caucasian man developed presumed cortical blindness due to $\mathrm{CO}$ poisoning following a suicide attempt when aged 49 . Like case 1 , he had redirected exhaust fumes to the interior of his sealed car. Details from his original assessment are scanty but it seems his vision had been poor since this time, although for social reasons he only presented to our service some 10 years after the original insult. Whilst his systemic neurological examination was unremarkable, he did have some deficits in cognitive functions, particularly long- and short-term memory, and his affect appeared dulled. His visual acuities were CF (count fingers) in either eye. Visual fields revealed bilateral central scotomata and peripheral constriction (Fig. 4). Fundoscopy showed bilateral temporal disc pallor. FVEPs were grossly delayed $(\mathrm{P} 100=160 \mathrm{~ms})$ and of PNP waveform from either eye. PERGs had reduced P50 components, with the N95 components being absent in the right eye and grossly reduced in the left. The P50/ N95 ratio is therefore significantly elevated (approaching infinity for the right). FERGs were normal from both eyes (Fig. 5, including normal examples).

\section{Cae 3}

A 30-year-old Caucasian man was exposed to exhaust fumes during a road traffic accident. He was trapped in his car after the accident but the engine continued running with misdirection of the fumes into the passenger space. He was unconscious when recovered by the emergency teams, who noted a strong smell of exhaust fumes. Despite the absence of any head injury he remained comatose for 6 weeks after the initial incident. Chemical pathological and neuroradiological investigations failed to indicate an underlying organic cause for his extended coma. He woke up complaining of poor vision, which was documented at 6/18 right and left. He was lost to follow-up for 3 years after which time he re-presented with poor vision. His visual acuities remained unchanged.

Fundoscopy revealed bilateral disc cupping (cup:disc ratio 0.7) and pallor. His visual fields showed a slight centrocecal defect to dim targets (Fig. 6).

VEPs were reduced in amplitude to flash and of normal amplitude but markedly delayed to pattern $(\mathrm{P} 100=130-140 \mathrm{~ms}$ right and left). PERGs had normal P50 components but absent N95 components for both eyes (Fig. 7).

\section{Results}

The ocular findings and the results of psychophysical and electrophysiological investigations are presented in Table 1.

\section{Discussion}

We have presented three patients who give a clear history of visual loss following exhaust fume exposure, two from suicide attempts and one during a road traffic accident. There is no single test, or combination of investigations, that can categorically show that $\mathrm{CO}$ has caused the visual deficits in these patients, but the circumstantial evidence of exhaust fume toxicity and the lack of any other cause is probably enough to constitute an aetiological link. In all cases the only clinical ophthalmic finding was optic nerve disease.

Farnsworth-Munsell colour vision testing was not available at the time of acute presentation and Ishihara

Table 1. Summary of findings in the three patients studied

\begin{tabular}{|c|c|c|c|c|c|c|c|c|c|c|c|c|c|c|}
\hline \multirow[b]{2}{*}{ Patient no. } & \multirow{2}{*}{$\begin{array}{c}\text { Age } \\
\text { (years) }\end{array}$} & \multirow[b]{2}{*}{ Sex } & \multicolumn{2}{|c|}{ Visual acuity } & \multicolumn{2}{|c|}{ Flash VEP } & \multicolumn{2}{|c|}{ Pattern VEP } & \multicolumn{2}{|c|}{ Pattern ERG } & \multicolumn{2}{|c|}{ Flash ERG } & \multicolumn{2}{|c|}{ Fundus } \\
\hline & & & $\mathrm{R}$ & $\mathrm{L}$ & $\mathrm{R}$ & $\mathrm{L}$ & $\mathrm{R}$ & $\mathrm{L}$ & $\mathrm{R}$ & $\mathrm{L}$ & $\mathrm{R}$ & $\mathrm{L}$ & $\mathrm{R}$ & $\mathrm{L}$ \\
\hline Case 1 & 43 & $\mathrm{~F}$ & & & & & & & & & & & & \\
\hline Pre-treatment ${ }^{\mathrm{a}}$ & & & $6 / 60$ & $6 / 36$ & PNP & PNP & $\begin{array}{l}\text { Delayed } \\
\text { (126 ms) }\end{array}$ & $\begin{array}{c}\text { Delayed } \\
(126 \mathrm{~ms})\end{array}$ & $\begin{array}{c}\text { Reduced } \\
\text { N95 }\end{array}$ & $\begin{array}{l}\text { Reduced } \\
\quad \text { N95 }\end{array}$ & Normal & Normal & Pale disc & Pale disc \\
\hline Post-treatment ${ }^{\mathrm{b}}$ & & & $6 / 36$ & $6 / 18$ & Normal & Normal & Normal & Normal & Normal & Normal & Normal & Normal & Pale disc & Pale disc \\
\hline Case 2 & 59 & M & $\mathrm{CF}$ & $\mathrm{CF}$ & $\begin{array}{c}\text { PNP } \\
\text { delayed }\end{array}$ & $\begin{array}{c}\text { PNP } \\
\text { delayed }\end{array}$ & $\begin{array}{c}\text { Reduced } \\
\text { delay }(160\end{array}$ & $\begin{array}{l}\text { with gross } \\
\text { ms R \& L) }\end{array}$ & $\begin{array}{l}\text { Absent } \\
\text { N95 }\end{array}$ & $\begin{array}{c}\text { Absent } \\
\text { N95 }\end{array}$ & Normal & Normal & Pale disc & Pale disc \\
\hline Case 3 & 30 & M & $6 / 18$ & $6 / 18$ & $\begin{array}{c}\text { PNP } \\
\text { reduced }\end{array}$ & $\begin{array}{c}\text { PNP } \\
\text { reduced }\end{array}$ & $\begin{array}{r}\text { Gross de } \\
(140\end{array}$ & $\begin{array}{l}\text { lay R \& L } \\
\text { ms) }\end{array}$ & $\begin{array}{c}\text { Absent } \\
\text { N95 }\end{array}$ & $\begin{array}{c}\text { Absent } \\
\text { N95 }\end{array}$ & Normal & Normal & $\begin{array}{c}\text { Pale disc, } \\
\text { cupping }\end{array}$ & $\begin{array}{c}\text { Pale disc, } \\
\text { cupping }\end{array}$ \\
\hline
\end{tabular}

VEP, visual evoked potential; ERG, electroretinogram; PNP, positive-negative-positive waveform.

${ }^{a}$ At presentation; bafter 4 months. 
plate testing, whilst not specifically described as being utilised, would have added little to the investigations already performed.

It would appear from the cases described above that $\mathrm{CO}$ poisoning can cause an optic neuropathy. There is also evidence, albeit from only one (case 1) of our three patients, that the toxic effects may be reversible if patients present soon enough. Our study supports the findings of others who have suggested that $\mathrm{CO}$ poisoning causes toxic neuropathy. ${ }^{6,7}$

In a normal VEP trace there is a positive, downwards deflection after $100 \mathrm{~ms}$ (P100). The so-called PNP waveform has a negative, upwards deflection sandwiched between two positive deflections. This waveform was not only present in cases 1 and 2 but it was also delayed. The appearance of a delayed PNP waveform has been described in cases of tobacco amblyopia and West Indian amblyopia, ${ }^{13-15}$ but it can reflect pathology anywhere along the central visual pathway, from optic nerve to occipital lobe. Animal studies have shown that $\mathrm{CO}$ poisoning and tobacco amblyopia produce similar abnormalities in the evoked potential. ${ }^{7}$ There may be a common final pathway between $\mathrm{CO}$ and cyanide in producing an optic neuropathy. This might explain the improvement seen in our first case following treatment with hydroxycobalamine.

The pattern ERG, using checkerboard stimuli, is a reflection of macular and optic nerve function. The normal averaged trace shows a positive, upwards deflection after $50 \mathrm{~ms}$ (P50) and a negative, downwards, deflection after $95 \mathrm{~ms}$ (N95). Optic nerve disease can cause a reduction in the amplitude of the N95 component, particularly in cases of optic atrophy. ${ }^{16,17}$

A combination of an abnormal pattern ERG together with the presence of optic disc pallor, with particular involvement of the N95 component and a delayed VEP of PNP waveform, would suggest an underlying optic neuropathy rather than cerebral cortical damage. ${ }^{12,16,17}$ From our evidence, therefore, we conclude that $\mathrm{CO}$ poisoning causes a toxic neuropathy that may have a similar aetiological mechanism to that in tobacco amblyopia. It is possible that the optic nerve damage caused may be, at least in part, reversible and thus, as in cases of tobacco amblyopia, may benefit from treatment with hydroxycobalamine. There may even be a place for prophylactic treatment with vitamin $\mathrm{B}_{12}$ in patients suffering acute $\mathrm{CO}$ poisoning.

\section{References}

1. Silverman IE, Galetta SL, Gray LG, Moster M, Atlas SW, Maurer, AH, Alavi A. SPECT in patients with cortical visual loss. J Nucl Med 1993;34:1447-51.

2. Quattrocolo G, Leotta D, Appendino L, Tarenzi L, Duca S. A case of cortical blindness due to carbon monoxide poisoning. Ital J Neurol Sci 1987;8:57-8.

3. Katafuchi $Y$, Nishimi T, Matsuishi T, Kimura Y, Otaki E, Yamashita $Y$. Cortical blindness in acute carbon monoxide poisoning. Brain Dev 1985;7:516-9.

4. Sparr SA, Jay M, Drislane FW, Venna N. A historic case of visual agnosia revisited after 40 cases. Brain 1991;114:789-800.

5. Vieregge P, Klosterman W, Blumm RG, Borgis KJ. Carbon monoxide poisoning: clinical, neurophysiological and brain imaging observations in acute disease and follow up. J Neurol 1989;236:478-81.

6. Zagami AS, Lethlean AK, Mellick R. Delayed neurological deterioration following carbon monoxide poisoning. J Neurol 1993;240:113-6.

7. Oku H, Fukushima K, Miyata M, Wakakura M, Ishikawa S. Cyanide with vitamin $\mathrm{B}_{12}$ deficiency as the cause of experimental tobacco amblyopia [English abstract]. Nippon Ganka Gakkai Zasshi 1991;95:158-64.

8. He F, Liu X, Yang S, Xu G, Fang G, Fan X. Evaluation of brain function in acute carbon monoxide poisoning with multimodality evoked potentials. Environ Res 1993;60:213-26.

9. Arezzo JC, Simson R, Brennan NE. Evoked potentials in the assessment of neurotoxicity in humans. Neurobehav Toxicol Teratol 1985;7:299-304.

10. Marmor MF, Arden GB, Nilsson SEG, Zrenner E. Standard for clinical electroretinography: International Standardisation Committee. Arch Ophthalmol 1989;107:816-9.

11. Marmor MF, Holder GE, Porciatti V, Trick GL, Zrenner E. Guidelines for basic pattern electroretinography. Doc Ophthalmol 1996;91:291-8.

12. Holder GE. Delayed VEPs: retinal or optic nerve disease? Electroencephalogr Clin Neurophysiol 1988;96:72-3.

13. Halliday AM. Visually evoked responses in optic nerve disease. Trans Ophthalmol Soc UK 1976;96:372-6.

14. Kriss A, Carroll WM, Blumhardt LD, Halliday AM. Pattern and flash evoked potentials in toxic (nutritional) optic neuropathy. In: Courjon J, Maugiere F, Revol M, editors. Clinical applications of evoked potentials in neurology. New York: Raven Press, 1982: 11-9.

15. Harding GFA, Crews SJ, Good PA. VEP in neuro-ophthalmic disease. In: Barber C, editor. Evoked potentials. Lancaster: MTP Press, 1980:235-41.

16. Berringer TA, Jaeger W, Krastel A. Electrophysiology and colour perimetry in dominant infantile optic atrophy. Br J Ophthalmol 1991;75:49-52.

17. Berringer TA, Bird AC, Arden GB. Leber's hereditary optic atrophy. Ophthalmic Paediatr Genet 1989;10:211-27. 